\title{
" Medical Revalidation as Professional Regulatory Reform: Challenging the Power of Enforceable Trust in the United Kingdom"
}

\section{Abstract}

For more than two decades, international healthcare crises and ensuing political debates have led to increasing professional governance and regulatory policy reform. Governance and policy reforms, commonly representing a shift from embodied trust in professionals to state enforceable trust, have challenged professional power and self-regulatory privileges. However, controversy remains as to whether such policies do actually shift the balance of power and what the resulting effects of policy introduction would be. This paper explores the roll-out and operationalisation of revalidation as medical regulatory reform within a United Kingdom National Health Service hospital from 20122013, and its impact upon professional power. Revalidation policy was subject to the existing governance and management structures of the organisation, resulting in the formal policy process being shaped at the local level. This paper explores how the disorganised nature of the organisation hindered rather than facilitated robust processes of professional governance and regulation, fostering formalistic rather than genuine professional engagement with the policy process. Formalistic engagement seemingly assisted the medical profession in retaining self-regulatory privileges whilst maintaining professional power over the policy process. The paper concludes by challenging the concept of state enforceable trust and the theorisation that professional groups are effectively regulated and controlled by means of national and organisational objectives, such as revalidation. 


\section{Key Words}

Healthcare professional regulation; Regulatory reform; Medical Revalidation; Professional power; Enforceable trust; United Kingdom.

\section{Introduction}

Over a number of decades, professional governance and regulatory policy reforms have increased due to international healthcare crises. Ensuing political debates and concerns for patient safety have resulted in the introduction of healthcare professional regulatory policies seeking accountability and control of professional groups and individual professionals (Kuhlmann and Saks, 2008). In the United Kingdom (UK) in particular, major official public enquiries into healthcare scandals over the last three decades (for example, Commission for Health Improvement, 2001; Francis, 2013; Kirkup, 2015; Matthews, 2004; Pleming, 2005; Pauffley, 2004; Redfern, 2001; Ritchie, 2000) have attracted political interest. Subsequent recommendations for healthcare professional regulatory reform (Berwick, 2013; Smith, 2004; Kennedy Report, 2001) have initiated the inception of 'revalidation' to ensure quality of care and the safety of service users. Revalidation is a statutory government led, regulatory reform policy aimed at proactively assuring the continued fitness to practise of all registered and practising healthcare professionals within the UK (Department of Health, 2007). On a 5 yearly revalidation cycle, registered and practising doctors must demonstrate their continued fitness to practice through annual appraisal and the development of a professional portfolio.

Whilst revalidation is not a new concept within international healthcare professional regulation, revalidation marks the largest and potentially most significant development in the history of healthcare professional regulation within the UK. The introduction of revalidation by the General Medical Council (GMC) in 2012 placed a statutory requirement on registered medical professionals in the UK to provide proof of continued competence and fitness to practise post qualification. Such regulatory reform, arguably viewed as a form of 'accountability-based enforceable trust' (light, 
2010), poses challenges to self-regulatory privileges and professional freedom from external control (Archer et al., 2012). New health regulatory policies, such as revalidation, are noted to frequently challenge existing power structures of professional groups, however, controversy remains as to whether new policies do shift the state-profession balance of power, and what the resulting effects of health policy introduction would be (Kuhlmann and Saks, 2008). This paper seeks to address this gap in knowledge, by drawing on a year-long ethnographic case study of one UK hospital during the 2012-2013 rollout of medical revalidation in the UK. This paper presents empirical data which explores the real-time implementation of medical revalidation within the organisation, its impact upon professional power and the factors influencing the effective regulation of doctors.

\section{Sociological history of professional self-regulation}

Professional self-regulation has historically been underpinned by a 'regulative bargain' (Cooper et al., 1988 p.8) between the state, the professions and the public in recognition of professional monopoly over highly specialised knowledge and skill. Control over the content and terms of work, and the ability to be self-directing and self-regulating have traditionally been granted to professional groups, as the state and outsiders of such professional groups were assumingly unable to judge the performance of their professional work (Freidson, 1970b; Light, 1988). It can be argued that when considering professional regulation, that the term 'self-regulation' is more complex than the term suggests (Allsop and Mulcahy, 1996), however at micro levels of medical practice, the regulation of practice and performance evaluation has traditionally been managed within the profession (Waring, 2007). Historically founded upon autonomy-based professionalism (Light, 2010), the medical profession have been trusted to regulate themselves, free from interference and control (Freidson, 1970a).

Over the past three decades however, sources of market and political pressure have arisen questioning the legitimacy of autonomy-based traditional professionalism (Light, 2010; Waring et al. 
2010). Autonomous market behaviour and self-commercialisation, as well as publicised international healthcare scandals, have provoked questioning of unfettered autonomy and fuelled distrust in traditional professional self-regulation (Gray, 2004; Light, 2010). In response, and as a form of countervailing power against professions, the 'buyer's revolt' ensued driving axes of change and a subsequent multi-dimensional transformation of professional work (Light, 2010: 278). Notably, governance and regulation of the professions in particular has changed in nature in response to demands for tighter regulation of health professionals (Kuhlman and Saks, 2008; Saks, 2010) and to rebuild societal trust in the medical profession. The evolution of governance and regulation is central to notion of enforceable trust (Ferlie, 2010), and principles of accountability-based new professionalism are at the core of emerging healthcare professional regulatory reform.

Many authors have debated accountability-based new professionalism with the advent of New Public Management principles, clinical governance and performance management, and the impact of such countervailing power on the medical profession (Ferlie, 2010; Ferlie et al., 1996; Harrison, 2004; Waring, 2007). The impact of numerous regulatory, managerial and market reforms over the decades upon the medical profession, and the shifting balance of power between doctors and mangers, have been theorised as proletarianisation and deprofessionalisation. Proletarianisation was theorised due to the bureaucratisation of healthcare (Hardey, 1999; McKinlay and Arches, 1985; Weiss and Fitzpatrick, 1997) and deprofessionalisation, due to loss of professional autonomy and control over terms of their professional work (Gray, 2002; Haug, 1975; McKinlay and Stoeckle, 1988; Weiss and Fitzpatrick, 1997; Willis, 1989).

Conversely, as a countervailing power against markets, the medical profession in particular have been theorised to subvert forms of external control, such as regulatory, managerial and market reforms, in an attempt to protect attributes of professionalisation (Freidson, 1970a; 1970b) and professional power (Abbott, 1988; Freidson, 1986; Larkin, 1983; Larson, 1977; 2012; Waring 2007). Moving forward from the deprofessionalisation thesis whereby changing patterns of professional 
governance were theorised as a threat to professional autonomy, contemporary research and theorisation describes countervailing professional changes of 'restratification' (Freidson, 1994: 9) and more recently 're-professionalisation' (Waring, 2014: 688). Restratification and reprofessionalisation suggests the context of professionalism and professional practices are restructured within the profession in response to countervailing market power and the shift from historical embodied trust based on competency and reputation to enforceable, informed trust (Light, 2010; Speed and Gabe, 2013). Re-professionalisation in particular highlights the emergence of professional-managerial hybrids, whereby professionals in professional-managerial roles, either incidentally or willingly, are hybridising professionalism in organisational and policy contexts (McGivern et al., 2015a; Waring, 2014) in an attempt to retain professional power.

\section{Reforming of UK medical self-regulation: From embodied to enforceable}

\section{trust}

The introduction of revalidation as regulatory reform in the UK can be discussed in relation to the concept of accountability-based new professionalism and enforceable trust (Light, 2010; Speed and Gabe, 2013). Revalidation has developed as a consequence of distrust in self-regulatory function, a central concept of new professionalism, and has become an integral part of the UK National Health Service (NHS) modernisation agenda. Revalidation in the UK is described as a statutory mechanism that allows health professionals to demonstrate that they remain up-to-date and can demonstrate that they continue to meet the requirements of their professional regulator. Revalidation aims to confirm that the registrant is practising in accordance with their regulators' professional standards and identify poor practice where local systems are inadequate or absent (Health and Social Care Act, 2008). Informed by the concept of accountability-based enforceable trust (Light, 2010), revalidation represents the process of imposing professionalism 'from above', whereby national and organisational objectives seeking to regulate and control professional groups are external to, and 
outside the direct influence of, the profession. Evetts (2012) suggests that where standards of professionalism are imposed 'from above', the balance in control and power is thought to shift. The anticipated effects are power and control seized by the organisational and regulatory elites, as well as wider government structures, resulting in a loss of professional power and control 'from within'.

Evaluating the impact of regulation upon professional groups however is challenging, as regulatory processes are generally applied universally in circumstances where there are many other influences or pressures on the behaviour of those being regulated, provoking both positive and negative effects (Walshe and Boyd, 2007). Wider health policy literature acknowledges that successful implementation of regulation is further dependent on the organisational implementation approach adopted, such as top-down or bottom-up approach, ultimately influencing the operationalisation, interpretation, organisation, application and subsequent compliance in practice (Anderson and Sotir Hussey, 2006; Buse et al., 2012). There is existing debate within the literature regarding the enforceability and effectiveness of top-down governance processes within organisations. In times of challenge, it is recognised that the medical profession has demonstrated the ability to resist topdown governance and retain its professional power (McDonald et al., 2013; Spyridonidis and Calnan, 2011; Waring, 2007). Salter (2004) in particular discussed the failure of government to adequately enforce clinical governance, and highlighted how doctors were able to control operationalisation. This resulted in a stark contrast between the reality of clinical governance implementation and the Government proposed clinical governance ideology (Department of Health, 1998). Additionally, and specifically in relation to the national implementation of revalidation, Salter (2007) highlighted how the medical profession had battled for control over the revalidation policy process, resulting in a significant delay with National revalidation policy implementation.

The intended consequences of professional regulatory processes are to provide transparency against standards, expose poor regulation and poor performance and deliver improvements in healthcare (Hood and Heald, 2006). Professional regulation however can produce unintended consequences 
which are more difficult to detect and measure (Hood, 2006), such as superficial 'tick box' paperwork compliance, which neither reflects nor improves the nature of care in professional practice (Chamberlain, 2010; Hood, 2006; McGivern and Ferlie, 2007; McGivern and Fischer, 2010, 2012; McGivern et al., 2009; Walshe and Boyd, 2007; Waring, 2009). There is a body of literature which primarily focus on the relationship between regulation and behavioural compliance (Currie et al., 2009; Quick, 2011; Munro, 2011; Scraggs et al., 2012; Sutherland and Leatherman, 2006), demonstrating the continued challenging nature of regulating professional groups and the impact of these professional groups as countervailing power.

Taking these debates forward, health regulatory policies, such as revalidation, have been theorised to challenge existing professional power structures and enforce trust by means of accountabilitybased new professionalism, however controversy remains as to whether new policies do successfully shift the balance of power, and what the resulting effects of such health policy introduction would be (Kuhlmann and Saks, 2008; Salter 2004). Scholarly debates have therefore highlighted that the impact of governance and regulatory reform upon professional groups, and the ability of the state to effectively regulate professional groups remains open for investigation and questioning (Kirkpatrick et al., 2005; Waring 2007). This paper seeks to contribute to such debate by exploring the real-time implementation of medical revalidation within a UK NHS hospital, its impact upon professional power and the factors influencing the effective regulation of doctors.

\section{The study}

Fieldwork was undertaken over one year between October 2012 and October 2013 in one mediumsized English NHS District General Hospital. In assuming that reality is socially constructed within the healthcare setting, the author took an interpretive ethnographic case study approach to the study design (Denzin, 1996). The author deemed an interpretive ethnographic approach the most effective way of gaining an in-depth understanding of the operationalisation of revalidation in the 
organisation, and the resulting effects of its introduction on professional power. A single site study was therefore chosen to facilitate an in-depth enquiry to aid in the understanding and appreciation of nuances of emerging regulatory reform within a complex multi-disciplinary context.

The single site case study provided insightful nuanced research findings. In addition it was also opportunistic as open access to the research site had been granted as the research site was a former place of employment for the author. As a researcher within their own culture (Tota, 2004), strangeness was not a given but an achievement (Ybema and Kamsteeg, 2009). The author addressed this by self-reflection and 'deconstructing taken-for-granted understandings' (Ybema and Kamsteeg, 2009 p.111). Taking a career break, and being absent from the organisation between October 2011 and August 2012, aided this process and was a factor which enabled the author to 'make the familiar strange' (Van Maanen, 1995 p.20). The author had 15 years prior experience of working in the organisation, however the culture and daily working practices within the organisation on re-entering the field after 11 months were not familiar.

\section{Methods}

Posters informing staff of the research and the author's presence were displayed in all staff areas throughout the observation period. Participant information sheets were displayed in all staff areas, inviting their voluntary participation. Additionally, at initial face-to-face encounter the author confirmed staff were happy to be involved in the study; one doctor declined to take part due to an ongoing Fitness to Practise investigation. During the research process the author gathered data at organisational, departmental and individual professional levels. Data was generated through documentary analysis, in-depth interviews and observation. The author was present within the field for over 300 hours during the research period and non-participant observation was conducted at managerial and departmental levels. Due to the confidential nature of appraisal meetings the author 
was unable to gain access and observe appraisal and revalidation recommendation meetings between appraisees and appraisers. Chronological fieldnotes were made contemporaneously in a journal, paying particular attention to raw format and thick description (Allen, 2010).

The author reviewed the archival and contemporary policy documents relating to revalidation, both locally and nationally. Documents that the author selected for analysis were Department of Health publications, professional regulator and professional body publications as well as local NHS Foundation Trust policy, guidance and literature. Documents were limited to these authors to ensure the reliability and authenticity of the document content and the ability to compare local and national policy. The author used the computer software NVivo 10 to assist an ethnographic content analysis approach to documentary analysis (Altheide, 1987). The author took a purposive sampling approach for interview selection as this method was most appropriate for selecting participants with a mixed level of skills and experience, in addition to recruiting management personnel (May, 2011). Both informal and formal interviewing techniques were adopted during the research (Hammersley and Atkinson, 2007). Informal interviewing consisted of conversational type discussion in practice areas with consenting staff about their revalidation experiences. During the research process two Trust management personnel responsible for revalidation implementation and 16 doctors consented to a formal interview (Table 1).

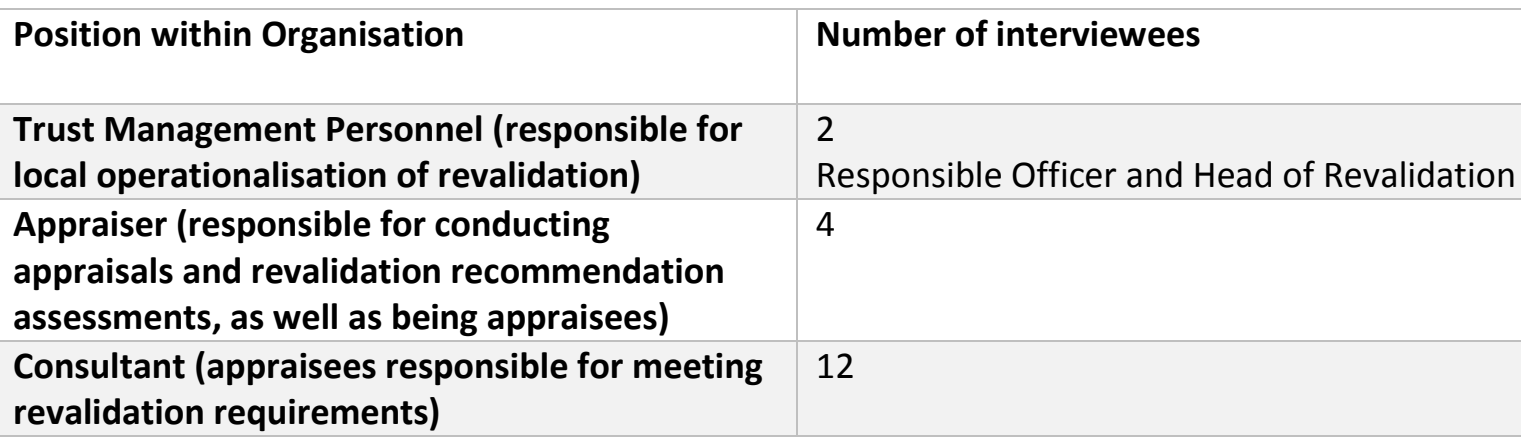

Consultant (appraisees responsible for meeting 12

\section{Number of interviewees}

2

Responsible Officer and Head of Revalidation

4

All formal interviews were conducted in private offices away from clinical areas and a topic guide was used to ensure a level of consistency. All interviews were electronically recorded and 
transcribed verbatim, and together with observational fieldnotes, the author used the computer software NVivo 10 to assist with organising and coding the data. The author took an iterative, inductive and constant comparative approach to data generation and analysis (Charmaz, 2006). Triangulation of fieldnotes and interview transcripts, and an iterative process of thematic coding (Hammersley and Atkinson, 2007), informed subsequent interview and observational activity. This process provided a framework for iterative coding and, with the triangulation of content documentary analysis, subsequent data categorisation and abstraction (Hammersley and Atkinson, 2007). The author was focused on exploring the operationalisation and effectiveness of revalidation policy at local level in comparison to national policy recommendations, as well as the impact such regulatory reform had upon professional regulatory power amongst the medical profession. Throughout the research process the NHS Research Governance Framework (Department of Health, 2005) was followed and ethical approval for the research was acquired from the Local Research Ethics Committee in August 2012 (Health Research Authority, 2016). Research approval and site access was granted from the Trust Research and Development department prior to commencement. This research was a University funded project as part of a Doctoral training programme.

\section{Results}

\section{Policy and Procedures for Medical Appraisal and Revalidation}

The team members who held responsibilities for the implementation of medical appraisal and revalidation included the Responsible Officer (RO), the Head of Revalidation (HoR), and 20 appraisers, who will be referred to as the Revalidation Implementation Team. The organisation did have a medical appraisal and revalidation policy in place which appeared to be informed by national GMC standards and guidance (GMC, 1998; 2010). The organisational policy reflected the national recommendation for medical appraisal and revalidation in that every non-trainee doctor had a 
timely, annual appraisal and a rolling five yearly cycle of revalidation. In order to achieve the aims of revalidation, the GMC required assurance that organisational systems of medical appraisal and clinical governance were functioning effectively and fairly in monitoring the conduct and performance of doctors, supporting appraisal and revalidation processes (GMC, 2013), and that ROs were able to make correct and valid revalidation recommendations (Revalidation Support Team, 2011). This assurance was provided by a two phase Organisational Readiness Self-Assessment (ORSA) for the implementation of revalidation. Prior to revalidation roll-out, the RO had submitted a positive self-assessment declaring organisational readiness for the implementation of revalidation. This positive self-assessment was self-confirmation that the organisation had the ability to support revalidation processes, in providing the appropriate resources and the required evidence to support robust annual medical appraisal processes. The systems required within the organisation in order to monitor conduct and performance, as well as support the organisational appraisal and revalidation processes, were multiple. These could be aligned to the types of supporting information required for the appraisal process (GMC, 2011) as detailed in Table one. Within the organisational policy, the RO was documented to have the responsibility to ensure that organisational systems were in place to enable individual doctors to obtain statistical data and other relevant information needed for their annual appraisal.

Table one: Types of Supporting Information required and corresponding governance process

\begin{tabular}{|l|l|}
\hline Supporting Information for Appraisal & Organisational Governance Process \\
\hline Continuing Professional Development & $\begin{array}{l}\text { Mandatory Training (Fire/Health \& } \\
\text { Safety) } \\
\text { Specialty Training (Specialty updates) } \\
\text { Role Specific (appraiser training) }\end{array}$ \\
\hline Quality Improvement Activity & $\begin{array}{l}\text { Clinical Audit Data } \\
\text { Clinical Outcomes Data } \\
\text { Case Note Review }\end{array}$ \\
\hline Significant Events & $\begin{array}{l}\text { Risk Management Data (untoward } \\
\text { incidents/never events) }\end{array}$ \\
\hline $\begin{array}{l}\text { Feedback from Colleagues \& } \\
\text { Feedback from Patients }\end{array}$ & 360 Feedback Process \\
\hline
\end{tabular}


Individual doctors were responsible for engaging with the annual appraisal and revalidation process, by compiling a portfolio of evidence and meeting with their appraiser annually. It was a joint responsibility of the appraiser and the appraisee to ensure that the required evidence was present and that the outcome of the annual appraisal and revalidation recommendation process were forwarded to the Responsible Officer for review and action as necessary. During the research process, however, it was evident that appraisal and organisational governance process issues, and the disorganised nature of the organisation, impacted upon the implementation of revalidation.

\section{Disorganised nature of the organisation}

Observational findings highlight the complex nature of day to day organisational life and how, in many ways, this particular organisation was far from organised. There was a top-down approach to policy implementation, and a frequent change of team personnel exacerbated a lack of organisation and poor communication within the Revalidation Implementation Team. The process of feedback escalation and the delegation of responsibility within the Revalidation Implementation Team detailed in the organisational policy (Figure 1) were markedly different to that observed by the author in practice (Figure 2). The office manager, an administrative worker, functioned as the Iynchpin of the Revalidation Implementation Team. The competing clinical and managerial workload pressures of the team led to a lack of time to meet as a team and a subsequent lack of communication between team personnel. Silo working had resulted whereby appraisers were taking responsibility for revalidation implementation at departmental level. This was exacerbated by the absence of a clear management structure and resulted in a lack of guidance and support across the Revalidation Implementation Team. 
Figure 1: The Revalidation Implementation Team responsibility (organisational policy)
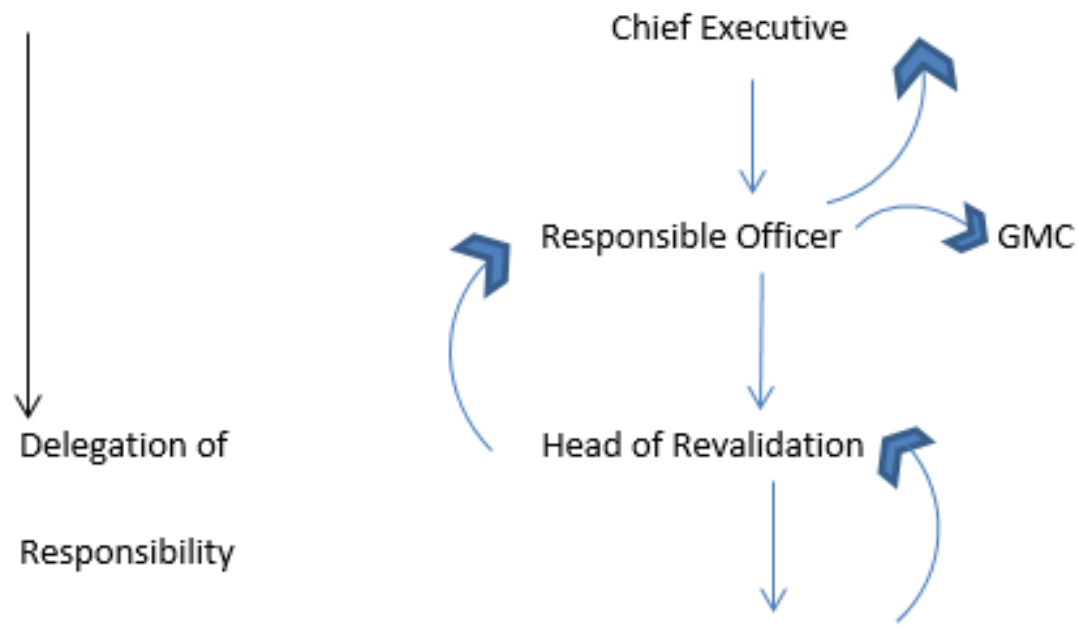

Feedback

Escalation

20 Appraisers

Figure 2: The Revalidation Implementation Team responsibility (observed)
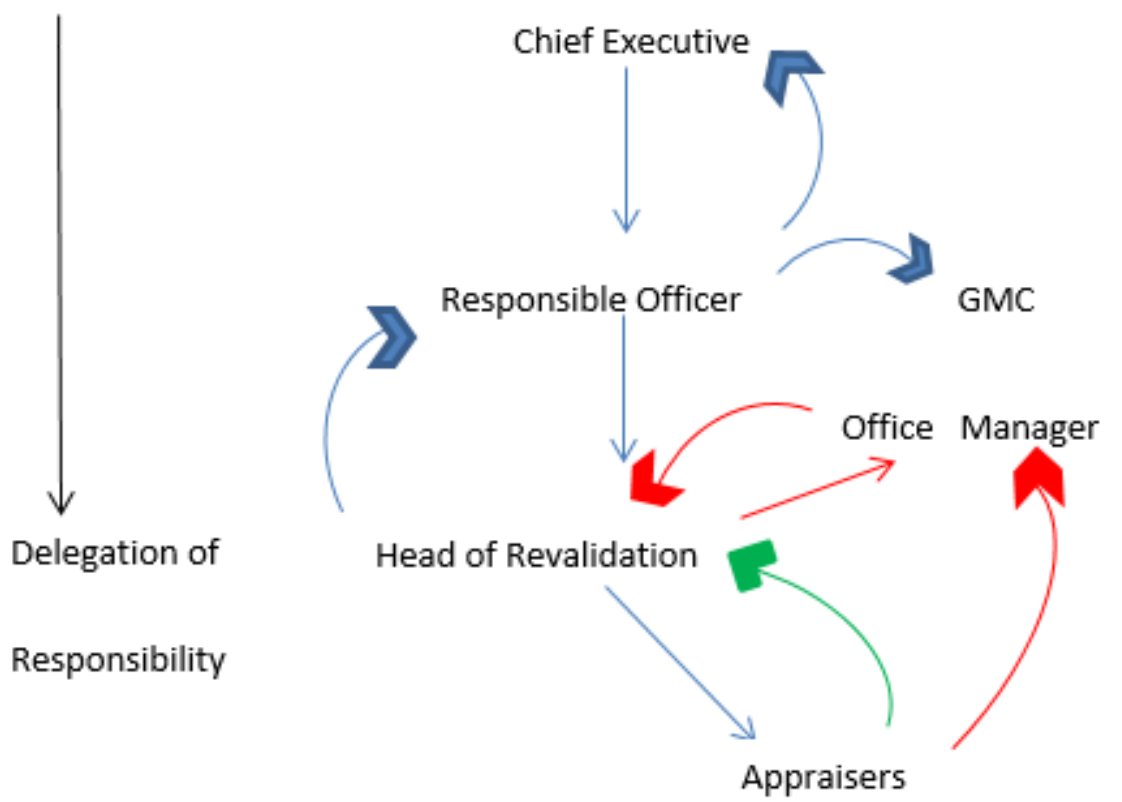

Feedback

Escalation

Responsibility

Appraisers

Green arrow signifies absence of planned feedback escalation

Red arrows signify observed feedback escalation

(Fieldnotes 180313) 
There was also a noted inconsistency in appraiser training within the organisation. As a consequence of differing levels of training and experience, the HoR reported that appraisers were approaching revalidation with differing approaches and perceptions of the policy process.

"50 percent [of appraisers] are actually saying maybe it's just a paper exercise and the other 50 percent are saying, no it's not...two ways to look at it really, I mean when I actually revalidated the first batch of doctors, I thought is it a paper exercise, or am I doing something right? And I took the way that I reviewed all their folders, all the appraisal folders to make sure that they are up to date, that they have got good feedback from their colleagues, that they have got good feedback from the patients... They have reflected on what they have learnt... On the other hand the other group of people...tick, tick, tick, tick, fine next" (Consultant 8/HoR).

The HoR also reported that differing approaches and perception of appraisers was in part due to the non-standardised appraisal system within the organisation.

"At the moment what's happening is we have still got a non-standardised paper based appraisal system. It's difficult to keep an eye on that because the doctors come and go from the Trust" (Consultant 8/HoR).

The non-standardised paper based appraisal system within the organisation was therefore highlighted as an ongoing challenge within the organisation. The lack of ability to ensure the robust, standardised implementation of the appraisal and revalidation policy was evident in further observations of the translation of organisational policy into local practice. In order to promote standardised departmental practices and limit manipulation of the appraisal and revalidation process, the organisational policy recommended that the appraiser was located within the same speciality as the appraisee. In reality however, appraisers frequently conducted appraisals outside their area of specialty due to appraisee choice. 
"I'm a gynaecologist and I personally appraise, well the last year was predominantly community paediatricians...two of the gynaecologists decided to come to me, an anaesthetist, a Consultant from A\&E...an Ophthalmologist, so a bit of a spread of different types of Consultants who decided to come to me" (Consultant 5/Appraiser).

The Revalidation Implementation Team therefore faced many challenges in leading the implementation of national revalidation policy recommendations within the organisation due to a lack of standardisation within the organisation.

\section{Appraisal and Organisational Governance Process Issues}

Despite the positive ORSA and the detailed organisational medical appraisal and revalidation policy, issues were identified with the effectiveness of appraisal and organisational governance processes during the implementation of medical revalidation at local level. The HoR acknowledged that the existing organisational IT and governance systems for providing supporting information to doctors to underpin appraisal and revalidation were inadequate, stating that the organisational governance systems did not provide doctors with the required data for their appraisal and revalidation assessment.

"...asking about complaints, and again about the serious untoward incidents that is a form of clinical governance that needs to be tightened up on...that's actually the responsibility of the organisation to provide that data to the individual doctor and we don't... we do not have the relevant IT processes to support revalidation requirements. The Trust has to play their role to provide the data, it has to be more transparent, it has to be more up to date" (Consultant 8/HoR).

Feedback from colleagues and patients was facilitated by an external company, based on an email system of feedback. The systems to provide complaints and significant events data however were 
not as formalised. Within the organisation each individual doctor had the responsibility of contacting the complaints and risk management departments to ask for personalised data for their appraisal and revalidation assessment. The lack of IT infrastructure to facilitate the gathering of supporting information for individual appraisal and revalidation meant that much of the evidence supporting non-involvement in untoward events, never events and complaints was written self-declaration of non-involvement. Data in the form of a printed report from the relevant departments was not expected as this was unobtainable. With self-declaration, there was an assumption that the individual doctor had contacted the relevant department for verification rather than their declaration being based on the fact that they had not been notified of any involvement in any complaints or untoward incidents by individual departments. Appraisers reported that a lack of robust purposeful data was a significant issue within the organisation, recognising that the data available within the organisation did not provide adequate assurance of fitness to practise. Appraisers acknowledged how being provided with individual complication rates and resource usage would be helpful in the assurance of fitness to practise of individuals.

"It would be very helpful for all of us [appraisers] to be able to say to somebody... why is it do you think you use twice as much blood as anyone else? Or why do you think your patients go back to theatre twice as often but that information is not to hand, which is a weakness. I'll bet you very few doctors in this country have the evidence, you'd say, and what's your complication rate with say vaginal hysterectomy? They'd say l've got no problems, you'd say, give us the evidence for that, and they say, there isn't any" (Consultant 7/Appraiser).

"I think it's a big failing at the moment that we [the organisation] don't provide data across all specialties. Cardiac surgeons now have to send in a lot of information...and so yes, there are true comparative databases going on in some of the specialities, I don't think enough at the moment though. It's certainly not done here [in Maternity]" (Consultant 5/Appraiser). 
The acknowledgment that such data was not available, coupled with the difficulties associated with the gathering of meaningful individual data as evidence, raised further worry amongst members of the Revalidation Implementation Team. The potential for manipulation of the appraisal process was a shared concern, expressing issues with the individual responsibility of the doctor in providing the required supporting information.

"...at the moment, it's the doctor's responsibility to provide that data for the appraisal... everybody's appraisal folder should say that he was involved in so many complaints, he was involved in so many serious untoward incidents... we should be spot on about providing the data about the individual's practice, but at the moment, it's not uniformly implemented. And I think people might manipulate onto that side of it, because it's not available and that is a real worry" (Consultant 8/HoR).

The HoR and appraisers expressed similar concerns about potential manipulation of the current system whereby data can be omitted from the appraisal and revalidation process, and the data presented is selected by the individual. This highlights two potential issues. The first being that appraisers reported, and the author observed, a variation in appraisee portfolios and a lack of robust evidence to support individual revalidation assessment. The existing appraisal process was acknowledged as being potentially flawed as data and information presented within the appraisal portfolio was selectively biased. This was based on the doctor choosing what data to include and then needing to generate this data. Secondly, there appeared to be an element of acceptance within the appraiser-appraisee relationship, in that the selectiveness of the data presented was acknowledged as not providing a true reflection of fitness to practise. This was evident in the acceptance of the limitations of the current organisational processes with no additional processes in place to validate the evidence presented by an appraisee, or to obtain the evidence that was omitted. 
This practice may have been symptomatic of long standing poor practices whereby appraisals have been historically conducted as an end in themselves regardless of the extent to which they are a meaningful interaction. This was evidenced in an archived version of the 'Policies and Procedures for Medical Appraisal and revalidation' which recommended that appraisal and revalidation assessments should still take place in the absence of supporting information. When the author reviewed the current version of the policy document, this sanction had been removed. The HoR stated this sanction had been removed to assist with revising the existing organisational appraisal process and to foster an expectation that individual appraisals should be informed by all of the evidence available to appraisers and appraisees. Interviewees however described appraisals as being conducted without the required data. Field observation, interviewee accounts and local documents suggest that minimal change had occurred in the way that appraisals were managed due to the continued use of non-standardised appraisal and revalidation processes, organisational governance process issues and inconsistent appraiser training and experience.

\section{Formalistic compliance at organisational and individual levels}

Despite the difficulties associated with medical appraisal and the 'successful' implementation of revalidation as previously highlighted, all medical professionals who had a revalidation assessment during the research process received a positive recommendation for revalidation by the appraisers. All medical professionals who had received a revalidation assessment were therefore recommended by the RO for successful revalidation, and were subsequently granted revalidation by the GMC. It was suggested by a consultant who had resigned from their role as an appraiser that the process of revalidation within the organisation had been reconstructed compared to the national policy.

"You had to provide more evidence [for revalidation], but you know...I think we have fudged it at this Trust ... we haven't got the core information that tells you whether I'm a good 
surgeon or not, and we should have really, we are supposed to be providing it, that's the thing...I think the Appraisers here have signed people off without seeing it" (Consultant 9).

The process of revalidation had also been interpreted by consultants as no different to the previous process of medical appraisal within the organisation, despite the national policy process aiming to strengthen the existing medical appraisal process.

"I think it's just a nice new name we are giving to something that we have been doing already" (Consultant 3).

This may arguably be due to the perception that little had changed with the revalidation process within the organisation, and that the required evidence for the revalidation assessment was not readily available. Consultants also expressed minimal personal benefit from engaging with the revalidation process.

"Well, from the point of view of being revalidated. All that's happened is that on the basis of my last appraisal, I've been revalidated... I can now go on a list which says the following doctor has been revalidated...my name will be there. That doesn't actually make any personal difference to me, apart from the fact that I don't have to worry about it again" (Consultant 7/Appraiser).

In addition, time was expressed as a significant barrier to engaging with revalidation.

MrX approached me to say 'I've been meaning to contact you, but just to let you know that I'm all up to date with revalidation and my appraisals, so you don't need to worry about me' They had assumed that I was to 'checking' that doctors within the organisation had gathered all of the required data for their appraisal and revalidation assessment. When I reassured the doctor about the aims and objectives of my research project, they divulged that their appraisal and revalidation discussion was the following month and they currently had no paperwork or data to support this assessment. Reasons for this were cited as the complex 
nature of gathering the data and a lack of time to generate the specific data required (fieldnotes 100513).

This scenario suggests that revalidation had been interpreted as an ad hoc paperwork and data gathering exercise rather than a culture change towards a continual process of professional development. Organisational and individual responses to revalidation implementation therefore support the notion of formalistic compliance in that the letter of regulatory direction (i.e. engagement with a statutory process) had become the primary goal, rather than the broader regulatory purpose (demonstrating the fitness to practise of doctors).

\section{Discussion}

Assuming that enforceable trust is achievable and that state regulation effectively regulates professionals, professionalism is assumed to be imposed 'from above', whereby national and organisational objectives regulate and control professional groups (Light, 2010; Speed and Gabe, 2013). This is opposed to professional groups being in control of bargaining with the state to secure and maintain its regulatory responsibilities 'from within'. Evetts (2012) suggests that where standards of professionalism are imposed 'from above', the balance in control and power is thought to shift. The anticipated effects are power and control seized by the organisational and regulatory elites, as well as wider government structure, resulting in a loss of professional power and control 'from within'.

Data presented within this paper however challenges the concept of enforceable trust. Due to organisational issues with revalidation implementation within the research site, the medical profession was able to subvert the full extent of scrutiny envisaged by the national policy of revalidation. This was primarily due to organisational barriers preventing effective revalidation 
implementation, thereby assisting doctors in maintaining professional power (Freidson, 1970a; 1970b). Findings highlight formalistic paperwork compliance (Chamberlain, 2010; Walshe and Boyd, 2007) with medical appraisal and revalidation. Within the organisation, a formalistic style of interaction with the GMC and wider regulatory policy had developed, and it appeared that compliance with the letter of regulatory direction (i.e. positive revalidation recommendations) had become the primary goal, rather than the broader regulatory purpose (assurance of fitness to practise).

Both national and organisational policy had been shaped by the internal processes of the organisation, and as such, local revalidation implementation did not mirror national policy guidance. During the research process however, every doctor received a positive outcome and was recommended to the GMC by the RO for revalidation. This suggests conformance behaviour, engaging with the formal processes of revalidation, but done solely to satisfy regulators and resulting in little if any value for service users or the organisation (Walshe and Boyd, 2007). This suggests that the RO had failed to fulfil their statutory responsibility in being able to fulfil the envisaged primary purpose of revalidation, in assuring that licensed doctors employed by the organisation were fit to practise (GMC, 2010a; Revalidation Support Team, 2013). Individuals occupying managerial roles were also limited in their ability to exercise control over fellow professionals, as they themselves were restricted by the 'disorganised' nature of the organisation. This scenario challenges the notion of enforceable trust (Light 2010). The individuals occupying organisational management and governance roles were neither able to exercise the personnel oversight required, nor regulate and control individual professionals by means of organisational objectives. The Revalidation Implementation Team was restricted by the organisational processes which existed to assist them with governing professionals, ultimately resulting in a failure to 'enforce' enforceable trust. 
As a consequence of ineffective organisational processes, medical professionals were able to directly and indirectly influence the implementation and management of revalidation and thereby maintain self-regulatory power. Therefore, despite the statutory policy of revalidation being imposed 'from above', the balance in control and power did not shift as anticipated with enforceable trust. Engagement with the policy process, however, did assist doctors in retaining an element of 'selfregulation' preserving a theorised core characteristic of health professionalism (Freidson, 1970a), whilst also maintaining professional power over the policy process (Freidson, 1986). Findings question the fitness for purpose of organisational regulatory processes in ensuring the competency and performance of individual professionals, and the regulatory process that ultimately determines whether individual professionals maintain their licence to practice. Due to the single site case study, the author cannot claim the findings are transferable to other organisations. The author calls for further research to extend, elaborate and examine the significance of these findings in other organisations.

\section{Conclusion}

This paper provides insight into the challenges of implementing national health policy at local level and its effect upon professional power. Data presented highlights the challenges in attempting to tightly regulate health professionals by means of national regulatory policy, due to the inefficiency of organisations and professionals, and their ineffectiveness in enforcing 'enforceable trust' (Light, 2010; Speed and Gabe, 2013). Data in this paper highlights the challenges associated with enforcing mechanisms of enforceable trust, such as revalidation, as control was not seized by the organisational and regulatory elites, or wider government structures as anticipated. As a result, medical professionals were able to directly and indirectly influence the implementation and management of revalidation and thereby maintain self-regulatory power. This paper supports the view that the scholarly debate regarding the ability of the state to effectively regulate professional 
groups remains open for investigation and questioning (Kirkpatrick et al., 2005; Waring 2007). Moreover, this paper indicates that the existing debate regarding enforceable trust, through topdown governance, does not adequately consider the impact of organisational factors and professional countervailing power upon the contemporary profession-state regulatory power struggle.

\section{References}

Abbott, A. (1988) The System of the Professions. London: University of Chicago Press.

Allen, D., (2010) Fieldwork and participant observation. In: Bourgeault, I., Dingwall, R., de Vries, R. (Eds.), SAGE Handbook of Qualitative Methods in Health Research. SAGE, London, pp. 353-372.

Allsop, J. and Mulcahy, L (1998) Maintaining Professional Identity: Doctor's Response to Complaints. Sociology of Health and IIIness 20(6) pp802-824.

Altheide, D. (1987) Ethnographic Content Analysis. Qualitative Sociology 10(1) pp65-77.

Anderson, G. Sotir Hussey, P. (2006) Influencing Government Policy In Pencheon, D. Guest, C. Melzer, D. Muir Gray, J. (eds) Oxford Handbook of Public Health. Oxford: University Press.

Archer, J. Regan De Bere, S. Nunn, S. Clark, J. and Corrigan, O. (2012) Revalidation: In Policy. Available at http://www.rcpsych.ac.uk/pdf/REVAL2013\%2012\%20Revalidation\%20in\%20Policy.pdf [Accessed 22 ${ }^{\text {nd }}$ January 2018].

Berwick, D. (2013) A Promise to Learn - A Commitment To Act: Improving the Safety of Patients in England. National Advisory Group on the Safety of Patients in England. Available at https://www.gov.uk/government/publications/berwick-review-into-patient-safety [Accessed 22nd January 2018]. 
Buse, K. Mays, N. Walt, G. (2012) Making Health Policy: Understanding Public Health 2nd Ed.

Berkshire: Open University Press.

Chamberlain, J. (2010) Portfolio-Based Performance Appraisal for Doctors. A Case of Paperwork Compliance. Sociological Research Online 15(1) 8. Available at

http://socresonline.org.uk/15/1/8.html [Accessed 22nd January 2018].

Charmaz, K. (2006) Constructing Grounded Theory: A Practical Guide through Qualitative Analysis. London: SAGE Publications.

Commission for Health Improvement (2001) Investigation into the Issues Arising From the Case of the Loughborough GP Peter Green. London: The Stationery Office.

Cooper, D. Lowe, A. Puxty, A. Robson, K. and Willmott, H. (1988) Regulating the UK Accountancy Profession: Episodes in the Relation between the Profession and the State. Paper presented at ESRC Conference on Corporatism at the Policy Studies Institute, London, January.

Currie, G. Humphreys, M. Waring, J Rowley, E. (2009) Narratives of Professional Regulation and Patient Safety: The Case of Medical Devices in Anaesthetics. Health, Risk \& Society 11(2) pp117-135. Department of Health (1998) A First Class Service: Quality in the New NHS. London: Department of Health.

Department of Health (2005) Research governance framework for health and social care. Retrieved from:

https://www.gov.uk/government/uploads/system/uploads/attachment data/file/139566/dh 08828 8.pdf [Accessed $22^{\text {nd }}$ January 2018].

Department of Health (2007) Trust, Assurance and Safety-The Regulation of Health Professionals in the 21st Century. Available at www.official-documents.gov.uk/document/cm70/7013/7013.pdf [Accessed 22 ${ }^{\text {nd }}$ January 2018]. 
Evetts, J. (2012) Professionalism in Turbulent Times: Changes, Challenges and Opportunities. Propel International Conference Paper, Stirling 9-11 May 2012. Available at

https://www.yumpu.com/en/document/view/12242124/full-paper-professionalism-in-turbulenttimes-changes-propel $\quad$ [Accessed $22^{\text {nd }}$ January 2018].

Ferlie, E. (2010) Public Management Reform Narratives and the Changing Organisation of Primary Care. London Journal of Primary Care 3(2) pp76-80.

Ferlie, E. Ashburner, L. Fitzgerald, L. and Pettigrew, A. (1996) The New Public Management in Action. Oxford: Oxford University Press.

Francis, R. (2013) Report of the Mid Staffordshire NHS Foundation Trust Public Inquiry: Executive summary. Available at:

www.midstaffspublicinquiry.com/sites/default/files/report/Executive\%20summary.pdf [Accessed $22^{\text {nd }}$ January 2018].

Freidson, E. (1970a) Profession of Medicine. New York: Dodd, Mead \& Co.

Freidson, E. (1970b) Medical Dominance. Chicago: Aldine-Atherton.

Freidson, E. (1986) Professional Powers. London: The University of Chicago Press.

Freidson, E. (1994) Professionalism Reborn: Theory, Prophecy and Policy. Chicago: University of Chicago Press.

General Medical Council (1998) Good Medical Practice. Available at https://www.gmc-

uk.org/good medical practice july 1998.pdf 25416527.pdf [Accessed 22nd January 2018]

General Medical Council (2010a) Revalidation - The Way Ahead. Available at http://www.gmcuk.org/static/documents/content/Revalidation way ahead annex1.pdf [Accessed 11th June 2016]. 
General Medical Council (2011) Supporting Information for Appraisal and Revalidation. Available at https://www.ndm.ox.ac.uk/ asset/file/supporting-information-for-appraisal-and-revalidationgmc.pdf [Accessed 22nd January 2018].

General Medical Council (2013) Effective Governance to Support Medical Revalidation. London: General Medical Council.

Gray, A. (2004) Governing Medicine: An Introduction In Gray, A. and Harrison, S. (eds) Governing Medicine: Theory and Practice. Berkshire: Open University Press.

Gray, D. (2002) Deprofessionalising Doctors? British Medical Journal 324(7338) pp627-628.

Hammersley, M., Atkinson, P., (2007) Ethnography: Principles in Practice. Routledge, London.

Hardey, M. (1999) Doctor in the House: The Internet as a Source of Lay Health Knowledge and the Challenge to Expertise. Sociology of Health and IIIness 21(6) pp820-835.

Harrison, S. (2004) Governing Medicine: Governance, Science and Practice In Gray, A. and Harrison, S. (eds) Governing Medicine: Theory and Practice. Buckingham: Open University Press.

Haug, M. (1975) The Deprofessionalization of Everyone? Sociological Focus 8(3) pp.197-213.

Health and Social Care Act (2008). London: Stationary Office. Available at https://www.legislation.gov.uk/ukpga/2008/14/contents [Accessed 22nd January 2018].

Health Research Authority (2016) HRA approval. Retrieved from: http://www.hra.nhs.uk/researchcommunity/applying-for-approvals/hra-approval/ [Accessed 22 ${ }^{\text {nd }}$ January 2018].

Hood, C. (2006) Gaming in Target world: The Targets Approach to Managing British Public Services. Public Administration Review 66(4) pp515-521.

Hood, C. Heald, D. (2006) Transparency: The Key to Better Governance? Oxford: Oxford University Press. 
Kennedy Report (2001) The Report of the Public Inquiry into Children's Heart Surgery at the Bristol Royal Infirmary 1984-1995. Available at

http://webarchive.nationalarchives.gov.uk/+/http://www.dh.gov.uk/en/Publicationsandstatistics/Pu blications/PublicationsPolicyAndGuidance/DH 4005620 [Accessed $22^{\text {nd }}$ January 2018].

Kirkpatrick, I. Ackroyd, S. and Walker, R. (2005) New Managerialism and Public Sector Professionalism. London: Palgrave.

Kirkup, B. (2015) The Report of the Morecombe Bay Investigation. Available at https://www.gov.uk/government/uploads/system/uploads/attachment data/file/408480/47487 M BI Accessible v0.1.pdf [Accessed 22nd January 2018].

Kuhlmann, E. and Saks, M. (2008) Rethinking Professional Governance: International Directions in Health Care. Bristol: Policy Press.

Larkin, G. (1983) Occupational Monopoly and Modern Medicine. London: Tavistock Publications.

Larson, M. (1977) The Rise of Professionalism: A Sociological Analysis. London: University of California Press.

Larson, M. (2012) The Rise of Professionalism: Monopolies of Competencies and Sheltered Markets. Newark: Transaction.

Light, D. (1988) Turf Battles and the Theory of Professional Dominance. Research in the Sociology of Health Care 7 pp203-225.

Light, D. (2010) Health-Care Professions, Markets, and Countervailing Powers In Bird, C. Conrad, P. Fremont, A. and Timmermans, S. (eds) Handbook of Medical Sociology. 6th Ed. Nashville: Vanderbilt University Press.

Matthews, S. (2004) Committee of Inquiry to Investigate How the NHS Handled Allegations About the Performance and Conduct of Richard Neale. London: The Stationery Office. 
May, T. (2011) Social Research. Issues, Methods and Process. 4th Ed. Berkshire: Open University Press.

McDonald, R. Cheraghi-Sohi, S. Bayes, S. Morriss, R. Kai, J. (2013) Competing and Coexisiting Logics in the Changing Field of English General Medical Practice. Social Science and Medicine 93 pp47-54.

McGivern, G. Currie, G. Ferlie, E. Fitzgerald, L. Waring, J. (2015) Hybrid Manager Professionals' Identity Work, the Maintenance and Hybridization of Medical Professionalism in Managerial Contexts. Public Administration 93(2) pp412-432.

McGivern, G. Ferlie, E. (2007) Playing Tick Box Games: Interrelating Defences in Professional Appraisal. Human Relations 60 pp1361-1385.

McGivern, G. Fischer, M. (2010) Medical Regulation, Spectacular Transparency and the Blame Business. Journal of Health Organisation and Management 24(6) pp597-610.

McGivern, G. Fischer, M. (2012) Reactivity and Reactions to Regulatory Transparency in Medicine, Psychotherapy and Counselling. Social Science \& Medicine 74(3) pp289-296.

McGivern, G., Fischer, M., Ferlie, E. Exworthy, M. (2009) The Visible and Invisible Performance Effects of Transparency in Medical Professional Regulation: Full Research Report. Swindon: ESRC.

McKinlay, J. and Arches, J. (1985) Towards the Proletarianisation of Physicians. International Journal of Health Services 18(2) pp191-205.

McKinlay, J. and Stoeckle, J. (1998) Corporatization and the Social Transformation of Doctors. International Journal of Health Services 18(2) pp191-205.

Munro, E. (2011) The Munro Review of Child Protection: Final Report: A Child-Centred System. Norwich: The Stationery Office. 
Pauffley, A. (2004) Independent Investigation into How the NHS Handled Allegations about the Conduct of Clifford Ayling. London: The Stationery Office.

Pleming, N. (2005) The Kerr/Haslam Inquiry. London: The Stationery Office.

Quick, O. (2011) A Scoping Study on the Effects of Health Professional Regulation on Those Regulated. Final Report submitted to the Council for Healthcare Regulatory Excellence. Available at https://www.professionalstandards.org.uk/docs/default-source/publications/research-paper/studyon-the-effects-of-health-professional-regulation-on-those-regulated-2011.pdf [Accessed 22nd January 2018].

Redfern, M. (2001) The Royal Liverpool Children's Inquiry Report. London: The Stationery Office. Revalidation Support Team (2011) Organisational Readiness Self-Assessment: End of Year Report 2010-11. Available at http://www.england.nhs.uk/revalidation/?s=ORSA\&paged=3 [Accessed 16th June 2016]

Revalidation Support Team (2013) Medical Appraisal Guide: A Guide to Medical Appraisal for Revalidation in England. Available at https://www.england.nhs.uk/revalidation/wpcontent/uploads/sites/10/2014/02/rst-medical-app-guide-2013.pdf [Accessed 22 ${ }^{\text {nd }}$ January 2018]. Ritchie, J. (2000) An Inquiry into Quality and Practice Within the NHS Arising From the Actions of Rodney Ledward. London: The Stationery Office.

Saks, M. (2010) Analyzing the Professions: The Case for the Neo-Weberian Approach. Comparative Sociology 9 pp887-915.

Salter, B. (2004) The New Politics of Medicine. Hampshire: Palgrave Macmillan.

Salter, B. (2007) Governing UK Medical Performance: A Struggle for Policy Dominance. Health Policy 82 pp263-275. 
Scraggs, E. Brereton, L. Newbould, J. Drabble, S. Tiefensee, C. Schweppenstedde, D. Miani, C. Ling, T. (2012) Factors That Encourage or Discourage Doctors From Acting In Accordance With Good Practice. Report to the General Medical Council (DRR-5728-GMC). Available at https://www.gmcuk.org/Barriers and enablers of good practice final research report.pdf 50388604.pdf [Accessed 22nd January 2018].

Smith, J. (2004) Safeguarding Patients: Lessons from the Past - Proposals for the Future. The Shipman Inquiry. London: Stationary Office.

Speed, E. and Gabe, J. (2013) The Health and Social Care Act 2012: The Extension of 'New Professionalism. Critical Social Policy 33(3) pp564-574.

Spyridonidis, D. and Calnan, M. (2011) Are new forms of professionalism emerging in medicine? The case of the implementation of NICE guidelines. Health Sociology Review 20(4) 394-409.

Sutherland, K. Leatherman, S. (2006) Regulation and Quality Improvement: A Review of the Evidence. London: Health Foundation.

Tota, A. (2004) Ethnographying Public Memory: The Commemorative Genre for the Victims of Terrorism in Italy. Qualitative Research 4 pp131-159.

Van Maanen, J. (1995) An End to Innocence: The Ethnography of Ethnography In Van Maanen, J. (eds) Representation in Ethnography. Thousand Oaks, CA: SAGE Publications.

Walshe, K. and Boyd, A. (2007) Designing Regulation: A Review. Available at https://www.escholar.manchester.ac.uk/uk-ac-man-scw:118421 [Accessed 22 ${ }^{\text {nd }}$ January 2018].

Waring, J. (2007) Adaptive Regulation or Governmentality: Patient Safety and the Changing Regulation of Medicine. Sociology of Health and IIIness 29(2) pp163-179.

Waring, J. (2009) Constructing and Reconstructing Narratives of Patient Safety. Social Science \& Medicine 69(12) pp1722-1731. 
Waring, J. (2014) Restratification, Hybridity, and Professional Elites: Questions of Power, Identity and Relational Contingency at the Points of 'Professional-Organisation Intersection'. Sociology Compass 8(5) pp688-704.

Waring, J. Dixon-woods, M. Yeung, K. (2010) Modernising Medical Regulation: Where Are We Now? Journal of Health Organisation and Management 24(6) pp325-342.

Weiss, M. Fitzpatrick, R. (1997) Challenges to Medicine: The Case of Prescribing. Sociology of Health and IIIness 19(3) pp297-327.

Willis, E. (1989) Medical Dominance: The Division of Labour in Australian Health Care. Revised Edition. Sydney: Allen and Unwin.

Ybema, S. and Kamsteeg, F. (2009) Making the Familiar Strange: A Case for Disengaged Organizational Ethnography In Ybema, S. Yanow, D. Wels, H. and Kamsteeg, F. (eds) Organizational Ethnography. Studying the Complexities of Everyday Life. London: SAGE Publications. 